\title{
A Study of Patient Satisfaction with Maxillary Anterior Teeth Restorations and Desirable Esthetic Treatment Options
}

\author{
Dr Rupal J Shah ${ }^{1}$, Dr Farheen G Malek ${ }^{2}$, Dr Preeti Agarwal ${ }^{3}$ \\ ${ }^{\text {I}}$ (Professor and Head, Dept. Of Prosthodontia, Govt. Dental College and hospital, Ahmedabad, India) \\ ${ }_{2}^{2}$ (Post Graduate student, Dept. Of Prosthodontia, Govt. Dental College and hospital, Ahmedabad, India) \\ ${ }^{3}$ (Assistant professor, Dept. Of Prosthodontia, Govt. Dental College and hospital, Ahmedabad, India)
}

\begin{abstract}
Method:650 patients participated in the study, divided into 4 age groups. A structured, interviewerguided questionnaire was used to identify patient satisfaction with their general dental appearance, cosmetic elements and desired treatments. Their maxillary anterior teeth status was classified into 4 groups: (1) Composite filling group (CFG) (2) Porcelain jacket crown group (PJCG) (3) Fixed partial denture group $(F P D G)(4)$ Removable partial denture group (RPDG). The participants judged appearance and tooth colour using 3-point scale: dissatisfied, moderately dissatisfied and satisfied. Their desired esthetic treatment options were assessed.

Results: The overall rating of satisfaction was moderate; almost $39.5 \%$ patients were completely satisfied with their dental appearance and tooth colour. A significant difference was observed for both the dental appearance and the tooth colour between different maxillary anterior teeth status groups and between different age groups $(p<0.05)$. The majority of individuals with CFG and FPDG were completely satisfied, while those with PJCG and RPDG were dissatisfied with their dental appearance and tooth colour $(p<0.05) .50 .9 \%$ patients wished to have their teeth whitened.

Conclusion: Aesthetic attitudes towards the maxillary anterior teeth appearance and colour differed both between different age groups and different maxillary anterior teeth status groups. Dissatisfaction with tooth color,protruding teeth and unesthetic fillings were common and females were more dissatisfied than males in appearance.Tooth whitening was the most desired treatment to improve the esthetics.
\end{abstract}

Keywords: Colour, Desired Treatment, Esthetics, Maxillary Anterior Teeth Status, Patient Satisfaction, Restorations.

\section{Introduction}

Dental appearance is an important feature in determining the beauty of a face, and thus plays a key role in human social interactions. Assessment of dental appearance, one of the most important aspects of dental aesthetics, mainly refers to the six maxillary anterior teeth as they are the most visible ones during communication, speech, functioning and smiling $[1,2]$.

Among the significant factors affecting overall dental appearance are tooth color, shape, and position; quality of restoration; and the general arrangement of the dentition, especially of the anterior teeth[3]. Furthermore, an aesthetically pleasing smile was found to depend on tooth color, size, shape, and position, upper lip position, amount of visibility of teeth and gingival display at rest and when smiling $[4,5]$.

Tooth color is one of the most important factors determining satisfaction with dental appearance[3]. As age advances, patient become unsatisfied with tooth color due to darkening. Furthermore, untreated dental caries, non-aesthetic or discolored anterior teeth restorations and missing anterior teeth usually lead to dissatisfaction with dental appearance [6-8]. And treatments improving dental aesthetics have been found to increase patient quality of life and psychological status $[9,10]$.

Previous studies have shown that, age has one of the most important influences on a patient's dental perception [11-13]. Middle aged subjects have more concerns about dental appearance and it decreases as age advances because of the loss of some or all their natural teeth, darker color or discoloration of their teeth, periodontal diseases and numerous dental restorations, which influence overall appearance of their maxillary anterior teeth.

The patient's attitude towards dental appearance is very important as it is proved to be effective on quality of life and general well-being and should be acknowledged in dental treatment decisions.

Currently, cosmetic dentistry has become an important aspect of dentistry. Tooth whitening treatments, anterior teeth restoration, labial veneers crowns, and orthodontic treatment are frequently demanded by patients who interested in improving their dental appearance [13].

We have assessed satisfaction with existing dental appearance, desired treatments to improve dental appearance, and factors that influence satisfaction with dental appearance among adult patients with different maxillary anterior teeth status. 


\section{Materials and Methods}

A total of 650 subjects who visited Outpatient Department of Government dental college \& hospital, Ahmedabad, participated in the study [323 men, 327 women].All the participants included in the study gave written informed consent to the survey procedures.

For the study of anterior teeth, the inclusion criteria were as follows: Individuals with any restorations on anterior teeth in the upper jaw [Composites Fixed partial dentures , Porcelain jacket crowns, Removable partial dentures]

Patients from 9 to 85 years were grouped in four different groups based on restorations on their on their upper anterior teeth

(1) Composite filling group (CFG)

(2) Porcelain jacket crown group (PJCG)

(3) Fixed partial denture group (FPDG)

(4) Removable partial denture group (RPDG)

For the purposes of the study, patients were also divided into four age groups:

1) Group $1(<20$ years )

2) Group 2 (21-40 years)

3) Group 3 (41-60 years)

4) Group 4 ( >60 years)

Patients were then asked to complete a questionnaire and assess their satisfaction with the dental appearance and colour of their maxillary anterior teeth using a likert three-point scale with possible answers 'dissatisfied', 'moderately satisfied', or 'completely satisfied'.

This study also included patient's satisfaction with his/her then-current general dental appearance .A structured, interviewer guided questionnaire (Table 1) was used for data collection. The questionnaire consisted of questions on socio-demographic items including sex, age, and level of education. Patients were also asked about their satisfaction with tooth color, perceived malalignment of teeth (crowding, poorly aligned or protruding), caries in anterior teeth, non-aesthetic anterior tooth color restoration and presence of tooth fracture. In addition, patients were asked to select the aesthetic treatments they wished to undergo, including orthodontic treatment, crowns, tooth whitening, tooth color restorations and partial dentures.

Table 1 Questionnaire
A. $\quad$ Sex $\square$ Male $\square$ Female
B. Age: (years)
C. Education level: $\square$ Primary $\square$ Secondary $\square$ Post secondary $\square$ Tertiary

1. Are you satisfied with the general appearance of your teeth? S/MS/D

2. Are you satisfied with your tooth color?

$\mathrm{S} / \mathrm{MS} / \mathrm{D}$

3. Do you feel your teeth are crowded?

4. Do you feel your teeth are poorly aligned?

$\square$ Yes $\square$ No

$\square$ Yes $\square$ No

5. Do you feel your teeth are protruding?

$\square$ Yes $\square$ No

6. Do you have dental caries in your front teeth?

$\square$ Yes $\square$ No

7. Do you have non-aesthetic fillings in your front teeth? $\quad \square$ Yes $\square$ No

8. Do you have fractures in your front teeth? $\quad \square$ Yes $\square$ No

9. Do you wish to undergo these treatments to improve the appearance of your teeth?

a. Orthodontic treatment to realign teeth

$\square$ Yes $\square$ No

b. Tooth whitening

$\square$ Yes $\square$ No

c. Dental crowns

$\square$ Yes $\square$ No

d. Tooth coloured fillings

$\square$ Yes $\square$ No

e. Dentures

$\square$ Yes $\square$ No

10 Have you been satisfied with the composite restorations/crowns / bridges/ anterior RPD?

$\begin{array}{lc}\text { Aesthetics } & \text { S/MS/D } \\ \text { Colour } & \text { S/MS/D } \\ \text { Shape } & \text { S/MS/D } \\ \text { Glossy finish } & \text { S/MS/D }\end{array}$

$\mathrm{S}=$ satisfied, $\mathrm{MS}=$ moderately satisfied, $\mathrm{D}=$ dissatisfied 
All procedures followed were in accordance with the ethical standards of the responsible committee on human experimentation (institutional and national) and with the Helsinki Declaration of 1975, as revised in 2008 (5). Informed consent was obtained from all patients for being included in the study.

The data were analysed using SPSS 18.0 statistical software (SPSS Inc., Chicago, IL, USA). The chi square test was used to compare the rates of patients' satisfaction with their dental appearance and tooth colour between different age and maxillary anterior teeth status groups $(p<0.05)$. Factors influencing patient satisfaction with dental appearance were determined at both the univariate and multivariate levels using simple logistic regression analysis and multiple logistic regression analysis, respectively.

\section{Results}

A total of 650 patients participated in this study. Of these, $323(49 \%)$ were men and $327(51 \%)$ were women. At the time of investigation, the patients were aged between 9 and 85 years, 38(5.8\%) of them were in the group $1(<20$ years); $369(56.8 \%)$ in group $2(21-40$ years $) ; 188(28.9 \%)$ in group $3(41-60$ years $) ; 55(8.5 \%)$ in group 4 ( $>60$ years). [Table 2]

Table 2 Distribution of subjects selected for study $(n=650)$ Frequency $(\%)$

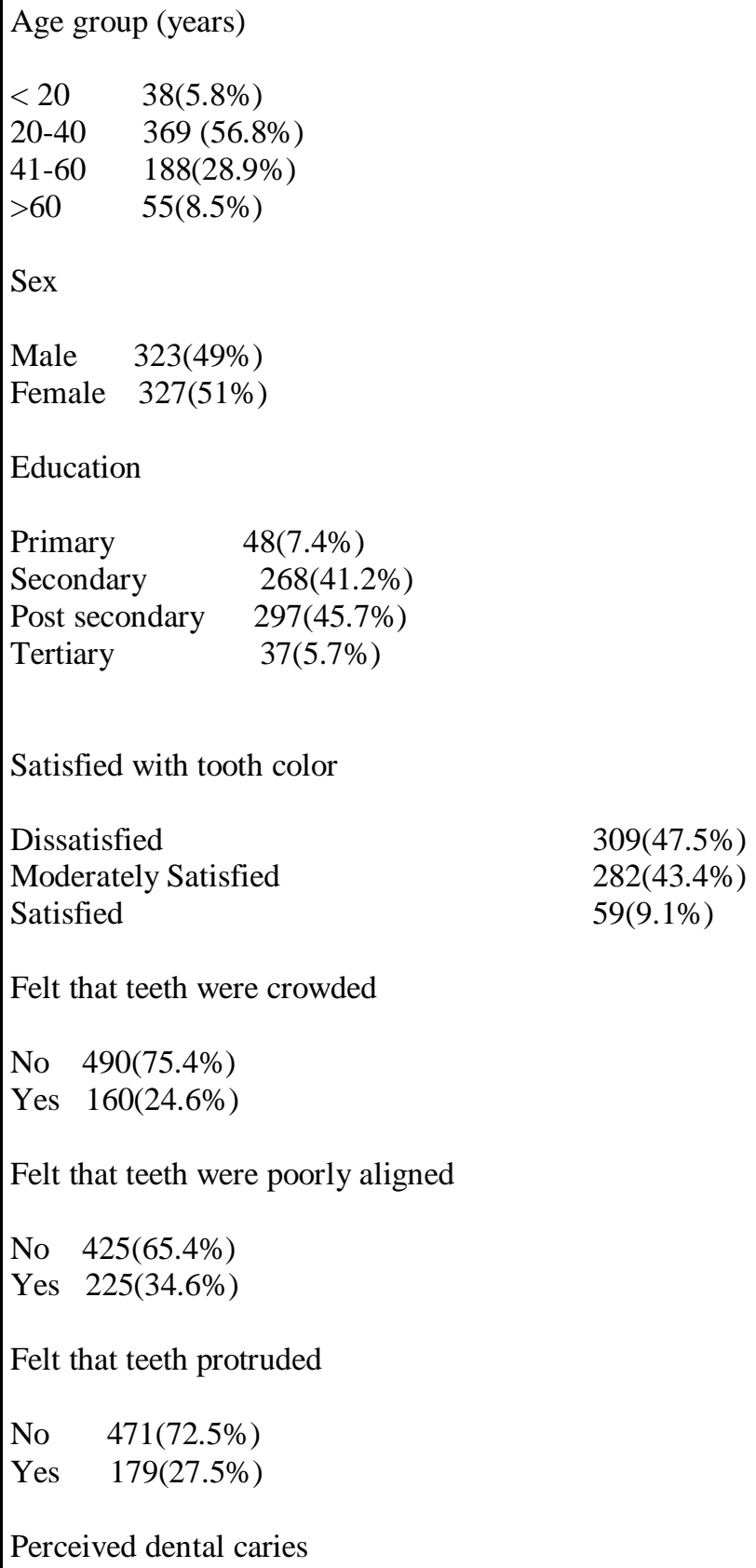

Felt that teeth were crowded

No $490(75.4 \%)$

Yes 160(24.6\%)

Felt that teeth were poorly aligned

No $425(65.4 \%)$

Yes $225(34.6 \%)$

Felt that teeth protruded

No $\quad 471(72.5 \%)$

Yes $179(27.5 \%)$

Perceived dental caries 


\begin{tabular}{|ll}
$\begin{array}{ll}\text { No } & 513(78.9 \%) \\
\text { Yes } & 137(21.1 \%) \\
\text { Perceived } & \text { non-aesthetic restorations } \\
\text { No } & 552(84.9 \%) \\
\text { Yes } & 98(15.1 \%) \\
\text { Perceived fractures } \\
\text { No } & 504(77.5 \%) \\
\text { Yes } & 146(22.5 \%)\end{array}$ \\
\hline
\end{tabular}

Attitudes and perceptions towards dental appearance differ among populations and among individuals in a population. We found that $(52.8 \%)$ of these patients were not happy with their general dental appearance, with dissatisfaction with tooth color being the most common $(59 \%)$. In addition, some patients regarded their teeth as poorly aligned $(34.6 \%)$, crowded $(24.6 \%)$, and protruding $(27.5 \%)$. Others reasons for dissatisfaction include self-reported presence of caries $(21.1 \%)$, non-aesthetic restorations $(15.1 \%)$, and tooth fractures $(22.5 \%)$.[Table 2]

Patients also answered questions about the treatments they desired to improve their appearance. We found that $50.9 \%$ wished to have their teeth whitened, followed by restoration of tooth color $(50.2 \%)$, dental crowns $(45.8 \%)$, orthodontic treatment (31.4\%) and dentures (16.9\%).[Table 3]

Table 3 Desired aesthetic dental treatments $(n=650)$

\begin{tabular}{|l|l|}
\hline Variables & Frequency (\%) \\
\hline Orthodontic treatment & $446(68.6 \%)$ \\
No & $204(31.4 \%)$ \\
Yes & $319(49 \%)$ \\
\hline Tooth whitening & $331(50.9 \%)$ \\
No & \\
Yes & $352(54.2)$ \\
\hline Dental crown & $298(45.8)$ \\
No & \\
Yes & $324(49.8)$ \\
\hline Tooth color restoration & $326(50.2)$ \\
No & \\
Yes & $540(83.1)$ \\
\hline Denture & $110(16.9)$ \\
\hline
\end{tabular}

Five hundred and thirty four (82.2\%) patients had fixed partial dentures on their upper anterior teeth (FPDG), $51(7.8 \%)$ had composite fillings, $42(6.5 \%)$ had porcelain fused-to-metal crowns on any of their upper anterior teeth (FPDG) and $23(3.5 \%)$ had RPD replacing any of anterior teeth.[Table 4]

Table 4. The distribution of the maxillary anterior teeth status in four different age groups

\begin{tabular}{|c|c|c|c|c|c|c|c|c|}
\hline & \multicolumn{5}{|c|}{$\begin{array}{l}\text { Maxillary anterior teeth status } \\
\text { (Frequency in numbers) }\end{array}$} & \multicolumn{3}{|c|}{ Chi square tests } \\
\hline $\begin{array}{l}\text { Age group } \\
\text { (Age in years) }\end{array}$ & COMPO & PJC & FPD & RPD & Total & Value & $\mathrm{df}$ & $\mathrm{p}$ value \\
\hline $\begin{array}{l}\text { Group 1 } \\
(<=20)\end{array}$ & 17 & 2 & 19 & 0 & 38 & \multirow{5}{*}{134.039} & \multirow{5}{*}{15} & \multirow{5}{*}{$<0.0001$} \\
\hline Group 2(21-40) & 26 & 33 & 307 & 3 & 369 & & & \\
\hline Group 3(41-60) & 6 & 4 & 163 & 15 & 188 & & & \\
\hline Group 4(>60) & 2 & 3 & 45 & 5 & 55 & & & \\
\hline Total & 51 & 42 & 534 & 23 & 650 & & & \\
\hline
\end{tabular}

$83 \%$ of age group 2 had FPD and $86 \%$ of age group 3 had FPD, while half of the group 1(46\%) and $7 \%$ of group 2 had composite restorations. Only $9 \%$ of group 3 had RPD replacing their anterior teeth. There was a significant difference in anterior dental status between different age groups $(\mathrm{p}<0.05)$ (Table 4).

The number of patients dissatisfied, moderately or completely satisfied with dental appearance and tooth colour in different age and maxillary anterior teeth status groups is shown in Table 5 and Table 6. 
The overall rating of satisfaction was moderate; almost $39.5 \%$ patients were completely satisfied with their dental appearance and tooth colour. However, a significant difference was observed for both the dental appearance and the tooth colour between different maxillary anterior teeth status groups as well as between different age groups $(\mathrm{p}<0.05)$ (Table 5).

Almost half of the Group 1,2 and 3 patients were completely satisfied with their dental appearance and color, while half of the group 4 patients were moderately satisfied ( $\mathrm{p}<0.05)$ (Table 5).

The majority of individuals with CFG and FPDG were completely satisfied, while those with PJCG and RPDG were dissatisfied with their dental appearance and tooth colour $(\mathrm{p}<0.05)$ (Table 6$)$.

Table 5 Satisfaction with dental appearance \& tooth color on age of the patients

\begin{tabular}{|c|c|c|c|c|c|c|c|c|}
\hline & Age group & Satisfy & Moderately Satisfy & Dissatisfy & Total & $\begin{array}{l}\text { Chi square } \\
\text { value }\end{array}$ & $\mathrm{df}$ & $\mathrm{P}$ value \\
\hline \multirow[t]{4}{*}{$\begin{array}{l}\text { Dental } \\
\text { appearance }\end{array}$} & $\begin{array}{l}\text { Group } \\
1(<20)\end{array}$ & 21 & 16 & 1 & 38 & \multirow[t]{4}{*}{30.496} & \multirow[t]{4}{*}{6} & \multirow[t]{4}{*}{$<.0001$} \\
\hline & $\begin{array}{l}\text { Group 2(20- } \\
40)\end{array}$ & 145 & 86 & 138 & 369 & & & \\
\hline & $\begin{array}{l}\text { Group 3(40- } \\
60)\end{array}$ & 73 & 58 & 57 & 188 & & & \\
\hline & $\begin{array}{l}\text { Group } \\
4(>60)\end{array}$ & 18 & 25 & 12 & 55 & & & \\
\hline \multirow[t]{4}{*}{ Tooth color } & $<20$ & 22 & 10 & 6 & 38 & \multirow{4}{*}{12.985} & \multirow{4}{*}{6} & \multirow{4}{*}{0.043} \\
\hline & $20-40$ & 116 & 173 & 80 & 369 & & & \\
\hline & $40-60$ & 69 & 76 & 43 & 188 & & & \\
\hline & $>60$ & 19 & 21 & 15 & 55 & & & \\
\hline
\end{tabular}

Table 6 Satisfaction with dental appearance $\&$ tooth color on maxillary anterior teeth status of the patients

\begin{tabular}{|c|c|c|c|c|c|c|c|c|}
\hline & $\begin{array}{l}\text { Anterior teeth } \\
\text { status }\end{array}$ & Satisfy & Moderately Satisfy & Dissatisfy & Total & $\begin{array}{l}\text { Chi square } \\
\text { value }\end{array}$ & $\mathrm{Df}$ & $P$ value \\
\hline \multirow[t]{3}{*}{ Dental appearance } & $\mathrm{CFG}$ & 23 & 9 & 19 & 51 & \multirow{3}{*}{17.407} & \multirow{3}{*}{6} & \multirow{3}{*}{.008} \\
\hline & PJCG & 8 & 12 & 22 & 42 & & & \\
\hline & RPDG & 7 & 5 & 11 & 23 & & & \\
\hline \multirow[t]{2}{*}{ Tooth color } & $\mathrm{CFG}$ & 21 & 26 & 4 & 51 & \multirow{2}{*}{24.024} & \multirow{2}{*}{6} & \multirow{2}{*}{.001} \\
\hline & RPDG & 5 & 6 & 12 & 23 & & & \\
\hline
\end{tabular}

Almost half of the Age Group1 patients were moderately satisfied with their dental appearance, while half of the Age Group 2 and Group 3 patients were completely satisfied ( $<$ 0.05) (Table 5). The majority of Age Group 1, 2 and 3 patients were completely satisfied with their dental appearance, but the majority of Age Group 4 individuals were just moderately satisfied $(\mathrm{p}>0.05)$. (Table 5)

Patients with high levels of education were found to be more satisfied with tooth colour or general dental appearance. Patients with secondary, post secondary and tertiary level of education are more satisfied with tooth colour compared to patient with primary level of education. [Fig 1]

Fig 1 satisfaction with color v/s education level

\section{Satisfaction with color $\mathrm{v} / \mathrm{s}$ education level}

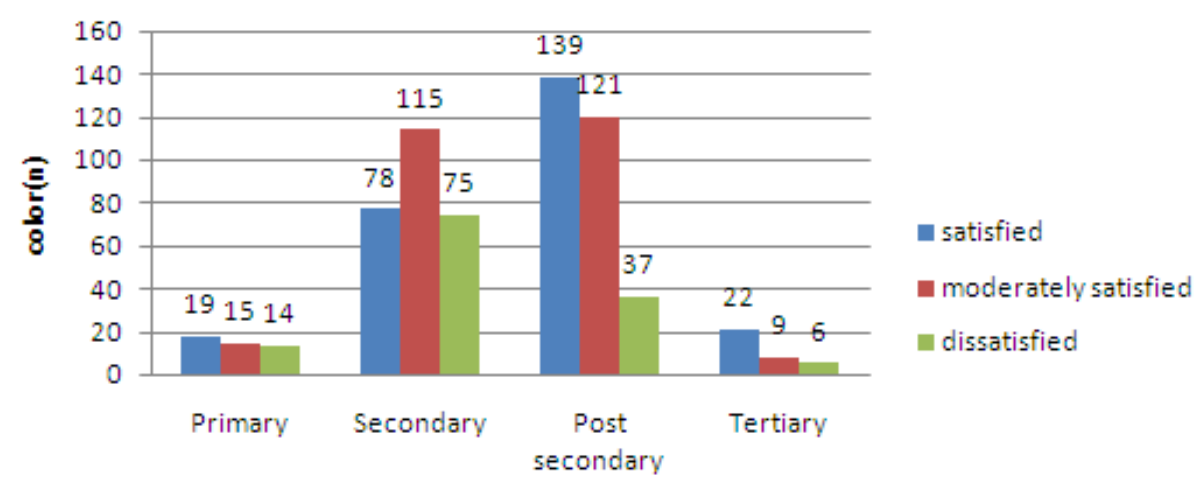

Education 
We found that satisfaction with dental appearance and color differed significantly between males and females. Females $(44 \%, 36 \%)$ are more dissatisfied than males $(19 \%, 8 \%)$. [Table 7]

Table 7 Maxillary anterior teeth aesthetics \& color satisfaction between gender

\begin{tabular}{|l|l|l|l|l|l|l|l|l|}
\hline & Sex & Satisfied & $\begin{array}{l}\text { Moderately } \\
\text { satisfied }\end{array}$ & Dissatisfied & Total & $\begin{array}{l}\text { Chi } \\
\text { square } \\
\text { test }\end{array}$ & df & p value \\
\hline \multirow{2}{*}{ Aesthetics } & Male & $163(50.5 \%)$ & $96(29.7 \%)$ & $64(19.8 \%)$ & 323 & & & \\
\cline { 2 - 9 } & Female & $94(28.7 \%)$ & $89(27.2 \%)$ & $144(44 \%)$ & 327 & 49.537 & 2 & $<0.0001$ \\
\hline \multirow{2}{*}{ Color } & Male & $161(49.8 \%)$ & $136(42.1 \%)$ & $26(8 \%)$ & 323 & & & \\
\cline { 2 - 9 } & Female & $65(19.9 \%)$ & $144(44 \%)$ & $118(36.1 \%)$ & 327 & 99.764 & 2 & $<0.0001$ \\
\hline
\end{tabular}

Simple logistic regression analysis of factors influencing patient satisfaction with dental appearance found no significant associations between patient satisfaction and age, perception of having crowded teeth, selfreported dental caries, and fractures of the anterior teeth.

However, Dissatisfaction with general dental appearance was significantly associated with protruding teeth $($ Odds ratio $(\mathrm{OR})=1.658,95 \% \mathrm{CI}$ (confidence interval): 1.624-1.693) and with their unesthetic filling in anterior teeth $(\mathrm{OR}=1.849,95 \% \mathrm{CI}: 1.822-1.877)$.

Multivariable logistic regression analysis showed that protruding teeth $(\mathrm{OR}=3.694,95 \% \mathrm{CI}: 2.610$ 5.227) with regarding their unesthetic filling in anterior teeth $(\mathrm{OR}=0.593,95 \% \mathrm{CI}$ : 0.382-0.921) were significant independent determinants of patient satisfaction with general appearance. [Table 8] No other dental problem or condition was associated with patient satisfaction with general dental appearance.

Table 8 Multivariable logistic regression analysis results

\begin{tabular}{|c|c|c|c|c|c|c|c|c|c|}
\hline \multicolumn{6}{|c|}{ Multivariable logistic regression analysis } & \multicolumn{4}{|c|}{ Tests of Homogeneity of the Odds Ratio } \\
\hline \multirow{2}{*}{$\begin{array}{l}\text { Dependent } \\
\text { Variable }\end{array}$} & \multirow[t]{2}{*}{ Mean } & \multirow[t]{2}{*}{ Std. Error } & \multicolumn{2}{|c|}{$95 \%$ Confidence Interval } & \multirow[t]{2}{*}{$\mathrm{p}$ value } & \multirow[t]{2}{*}{ Odd ratio } & \multicolumn{2}{|c|}{$95 \%$ Confidence Interval } & \multirow[t]{2}{*}{$\mathrm{p}$ value } \\
\hline & & & $\begin{array}{l}\text { Lower } \\
\text { Bound }\end{array}$ & $\begin{array}{l}\text { Upper } \\
\text { Bound }\end{array}$ & & & Lower Bound & Upper Bound & \\
\hline Color & 1.806 & 0.029 & 1.750 & 1.863 & $<0.0001$ & - & - & - & \\
\hline Crowding & 1.754 & 0.017 & 1.721 & 1.787 & 0.524 & 0.890 & 0.623 & 1.272 & 0.523 \\
\hline Poorly aligned & 1.654 & 0.019 & 1.617 & 1.691 & 0.844 & 1.033 & 0.748 & 1.427 & 0.844 \\
\hline Protruding & 1.658 & 0.018 & 1.624 & 1.693 & $<0.0001$ & 3.694 & 2.610 & 5.227 & $<0.0001$ \\
\hline Caries & 1.789 & 0.016 & 1.758 & 1.821 & 0.243 & 0.798 & 0.547 & 1.165 & 0.243 \\
\hline $\begin{array}{l}\text { Non-esthetic } \\
\text { fillings }\end{array}$ & 1.849 & 0.014 & 1.822 & 1.877 & 0.019 & 0.593 & 0.382 & 0.921 & 0.020 \\
\hline Fractures & 1.775 & 0.016 & 1.743 & 1.808 & 0.393 & 0.851 & 0.589 & 1.231 & 0.393 \\
\hline
\end{tabular}

\section{Discussion}

Attitudes and perceptions towards dental appearance differ among populations and among individuals in a population [14].We found that of adults attending the outpatient department of GDCH, only $39.8 \%$ were satisfied with the appearance of their teeth, a lower percentage than in previous studies of different populations. For example, a study of 1,014 patients at a dental school in Ankara, Turkey found that (57.3\%) were satisfied with their dental appearance as were $76 \%$ of stratified sample of adults in the United Kingdom[11].

Perception towards dental appearance is determined by cultural factors and individual preferences varying between individuals and cultures and changing over time. In general, older people (age 60 and above) were more satisfied with their dental appearance than younger people suggesting that the appearance of their teeth is not as important to older as to younger individuals $[11,14]$.

We expected that in older individuals, their interest in dental appearance would be diminished, together with the lower socio-economic status of older patients and their lower incomes (they are not able any more to afford very expensive aesthetic restorations).

The overall rating of satisfaction in this study was high; although some of the patients were not at all satisfied with their dental appearance, a high level of satisfaction with dental appearance and tooth colour was found, with almost half of the patients (43\%) completely satisfied. With regard to the older population in this study (60 years of age and older), approximately $79.20 \%$ were completely or moderately satisfied with dental appearance and tooth colour, which is in agreement with the outcome of Meng's study, where $75 \%$ of older people also appeared to be very satisfied and satisfied with their dental appearance[12], as well as Alkhatib's study in the UK population, where $80.3 \%$ of the $55+$ were satisfied with their dental appearance and $71.1 \%$ were satisfied with their tooth colour[11]. 
Furthermore, in the industrialised countries, the proportion of the elderly in society grows substantially and the characteristics of this group are of major interest for the community today.

In contrast with the significant age difference in patient's satisfaction with the dental appearance, where most of the younger were just moderately satisfied (probably due to the higher level of aesthetic expectation associated with the large media influence) and the other age groups were either moderately or completely satisfied (these results are in accordance with Alkhatib's[11]), the significant difference in satisfaction with tooth colour between younger and older age groups was not found ( $p>0.05)$ (Table 2).

So far, our findings were similar to those from Alkhatib's study, but they have failed to include dental status as one of the most important factors influencing the patient's attitudes toward their dental appearance and tooth colour in prosthodontically restored teeth.

Therefore, we divided our study group into the four (1) Composite filling group (CFG) (2) Porcelain jacket crown group (PJCG) (3) Fixed partial denture group (FPDG) (4) Removable partial denture group (RPDG)

In the young aged CFG, the majority of individuals were completely satisfied with their dental appearance and tooth colour. This was expected because of their awareness of oral health maintenance. On the contrary, the majority of middle and older CFG individuals were only moderately satisfied with their dental appearance and tooth colour, probably because their remaining natural teeth might exhibit colour changes and therefore teeth appear darker and due to the material characteristics of the restorations. Composite filling is the most common restoration in maxillary anterior teeth, because of its low price in comparison to prosthetic restoration. Although it can be completed in a single treatment session with no added laboratory cost, this material is presently limited by several restrictions - inability to completely replicate natural teeth in colour, low wear resistance, surface porosity and polymerisation- induced shrinkage, which certainly influence the patient's level of satisfaction [15].Therefore, these materials need to improve their performance.

In the FPDG, approximately half of the middle aged and older patients were completely satisfied with their dental appearance and tooth colour. In the younger age group, the majority of them were moderately satisfied with their dental appearance and their tooth colour. These results were surprising because we expected older patients to be dissatisfied with prosthetic restorations, because of the awareness that they have lost some of their maxillary anterior teeth. It seems that the younger patients in the FPDG were dissatisfied for the mentioned reasons, and the older patients were completely satisfied, because the prosthodontic restorations achieved their aesthetic goal in terms of dental appearance and tooth colour more than composite ones. Another reason for their satisfaction could also be the fact that they compare their restored anterior maxillary teeth status with the status prior to prosthodontic treatment.

The results of the present study have shown that ageing is not the main factor determining the level of a patient's satisfaction, but that dental status plays an important role, as well.

Tooth color is a critical factor influencing satisfaction with smile appearance and specially with restored anterior teeth [3]. Perception of tooth color is a complex phenomenon that is influenced by many factors including lighting conditions, the optical properties of teeth and restorative material (translucency, opacity, scattering of light, surface gloss), and the viewer's visual experience [16] .In agreement with previous results, we found that, dissatisfaction with tooth color may be the primary reason for dissatisfaction with dental appearance [13].

The important contribution of tooth color to patients' satisfaction with dental appearance was further highlighted by our finding that tooth whitening was the aesthetic treatment most desired by participants, a finding similar to previous results [13].

Many of the patients in this study reported having dental caries and non-aesthetic restorations in their front teeth, with and some reported having tooth fractures. All of these conditions will undoubtedly affect the appearance of teeth, presumably leading to patient dissatisfaction with general dental appearance. Although our patients in this study were not significantly affected by any of those conditions a previous study [13] reported that patient satisfaction with dental appearance was significantly influenced by self-reported caries in anterior teeth, but not by other conditions. Further, decayed anterior teeth were shown to have negative impact on perceptions of facial attractiveness [17].

Patients with high levels of education were found to be more satisfied with the colour of their teeth than individuals with lower academic achievement [5,7] as well as to have a lower preference for white teeth[14].These findings suggested that the higher self-satisfaction with tooth colour observed in individuals with higher academic achievement may reflect higher self-esteem[5,7].Among our patients also, Patients with high levels of education were found to be more satisfied with tooth colour or general dental appearance.

It is a commonly thought that women are more interested in their appearance than men. Indeed, female patients were found to be more concerned with their dental appearance than males [14] as well as to be more critical in judging their dental appearance[18]. Similar to previous results, we found that women expressed greater dissatisfaction with dental appearance and tooth color than men. 
Increased labio-lingual inclination of the anterior teeth may has caused some patients to regard that their teeth as protruding, another factor that influenced patient satisfaction with general dental appearance. We found that, other tooth malalignments did not affect patient satisfaction with general appearance, although selfreported poorly aligned teeth and upper anterior crowding have been found to be associated with patient's satisfaction [13].

Poor tooth alignment and crowding are among the most common malocclusion traits reported in the literature [19, 20 ], which may explain our finding of a lack of association between patients' perceptions of having these traits and satisfaction with general dental appearance.

\section{Conclusion}

Most patients in this study expressed dissatisfaction with their dental appearance. Dissatisfaction was more common in females than in males. Unhappiness with tooth color and feelings of having protruding teeth also had significant negative influences on patient satisfaction with their general dental appearance. The importance of tooth color was further supported by our finding that most patients would have liked to have their teeth whitened. Aesthetic attitudes towards the maxillary anterior teeth appearance and colour differed both between different age groups and different maxillary anterior teeth status groups. This must be acknowledged in treatment planning and should be considered along with the function of the future restoration.

\section{References}

[1]. Albashaireh ZSM, Alhusein AA, Marashdeh MM. Clinical assessments and patient evaluations of the esthetic quality of maxillary anterior restorations.Int J Prosthodont 2009; 22: 65-71.

[2]. Wolfart S, Quaas AC, Freitag S, Kropp P, Gerber WD, Kern M. Subjective and objective perception of upper incisors. J Oral Rehabil 2006; 33: 489-495.

[3]. Qualtrough A, Burke F: A look at dental esthetics. Quintessence International 1994, 25(1):7-14.

[4]. Duarte S Jr, Schnider P, Lorezon AP. The importance of width/length ratios of maxillary anterior permanent teeth in esthetic rehabilitation. Eur J Esthet Dent 2008; 3: 224-234.

[5]. Desai S, Upadhyay M, Nanda R. Dynamic smile analysis: changes with age. Am J Orthod Dentofacial Orthop 2009; 136: 310-311.

[6]. Akarslan Z, Sadik B, Erten H, Karabulut E: Dental esthetic satisfaction,received and desired dental treatments for improvement of esthetics.Indian Journal of Dental Research 2009, 20(2):195-200.

[7]. Al-Omiri M, Karasneh J, Lynch E, Lamey P, Clifford T: Impacts of missing upper anterior teeth on daily living. International Dental Journal 2009, 59(3):127-132.

[8]. Gerritsen A, Sarita P, Witter D, Kreulen C, Mulder J, Creugers N: Esthetic perception of missing teeth among a group of Tanzanian adults. The International Journal of Prosthodontics 2008, 21(2):169-173.

[9]. John M, Slade G, Szentpétery A, Setz J: Oral health-related quality of life in patients treated with fixed, removable, and complete dentures 1 month and 6 to 12 months after treatment. The International Journal of Prosthodontics 2004, 17(5):503-511.

[10]. Grossmann A, Hassel A, Schilling O, Lehmann F, Koob A, Rammelsberg P: Treatment with double crown-retained removable partial dentures and oral health-related quality of life in middle- and high-aged patients. The International Journal of Prosthodontics 2007, 20(6):576-578.

[11]. Alkhatib MN, Holt R, Bedi R. Age and perception of dental appearance and tooth color. Gerodontology 2005; 22: 32-36.

[12]. Meng X, Gilbert GH, Duncan RP. Satisfaction with dental appearance among diverse groups of dentate adults. J Aging Health 2007; 19: 778-791.

[13]. Samorodnitzky-Naveh GR, Geiger SB, Levin L. Patients' satisfaction with dental esthetics. J Am Dent Assoc 2007; 138: 805-808

[14]. Vallittu P, Vallittu A, Lassila V: Dental aesthetics-a survey of attitudes in different groups of patients. Journal of Dentistry 1996, 24(5):335-338.

[15]. Devoto W, Saracinelli M, Manauta J. Composite in everyday practice: how to choose the right material and simplify application techniques in the anterior teeth. Eur J Esthet Dent 2010; 5: 102-124.

[16]. Joiner A: Tooth colour: a review of the literature. Journal of Dentistry 2004, 32(Suppl 1):3-12.

[17]. Kershaw S, Newton J, Williams D: The influence of tooth colour on the perceptions of personal characteristics among female dental patients: comparisons of unmodified, decayed and 'whitened' teeth. British Dental Journal 2008, 204:E9.

[18]. Hassel A, Wegener I, Rolko C, Nitschke I: Self-rating of satisfaction with dental appearance in an elderly German population. International Dental Journal 2008, 58(2):98-102.

[19]. Jonsson T, Arnlaugsson S, Karlsson K, Ragnarsson B, Arnarson E, Magnusson T: Orthodontic treatment experience and prevalence of malocclusion traits in an Icelandic adult population. American Journal of Orthodontics and Dentofacial Orthopedics 2007, 131(1):8.e11-18.e18.

[20]. Borzabadi-Farahani A, Borzabadi-Farahani A, Eslamipour F: Malocclusion and occlusal traits in an urban Iranian population. An epidemiological study of 11- to 14-year-old children. European Journal of Orthodontics 2009, 31(5):477-484. 